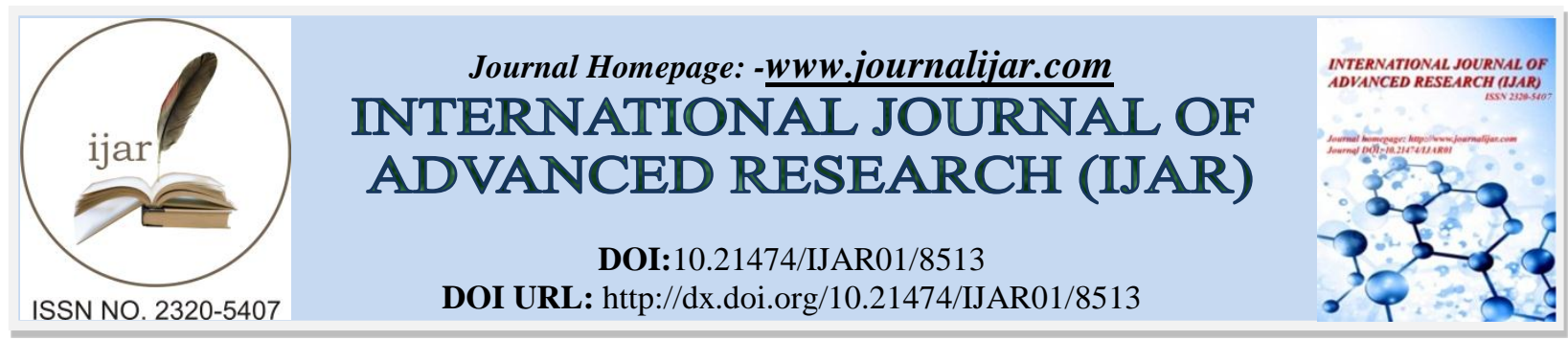

RESEARCH ARTICLE

\title{
INSECTICIDAL ACTIVITY OF CHENOPODIUM ALBUM AGAINST PLUTELLA XYLOSTELLA ON BRASSICA OLEACERA VAR. ACEPHALA.
}

Julião Monjane ${ }^{1}$, Raul Uane ${ }^{1}$ and Francisco Munguambe ${ }^{2}$.

1. Department of Chemistry, Eduardo Mondlane University, P.O. Box 257, Maputo, Mozambique.

2. Faculty of Agriculture and Forest Engineering, Eduardo Mondlane University, P.O. Box 257, Maputo Mozambique.

\section{Manuscript Info}

\section{Manuscript History}

Received: 06 December 2018

Final Accepted: 08 January 2019

Published: February 2019

Key words:-

Chenopodium album, Brassica oleacera,

Plutella xylostella, Insecticidal activity.

\begin{abstract}
The present work deals with the influence of the powders, aqueous and methanolic extracts of Chenopodium album plant on survival of the Brassica oleacera moth, Plutella xylostella (Diamondback moth), as well as, the phytochemical studies of the chemical constituents present in the leaves extract of $C$. album. The powders tested were obtained from the roots and the leaves of the plant. The insecticidal activity was evaluated using the leaf disc immersion method. The powders of the leaves $\left(\mathrm{IC}_{50}\right.$ value $100 \%$ at $0.1 \mathrm{~g}$ and $0.3 \mathrm{~g}$, respectively), powder of the roots $\left(\mathrm{IC}_{50}\right.$ values $77.5 \%$ at $0.1 \mathrm{~g}$ and $95.0 \%$ at $0.3 \mathrm{~g}$ ), aqueous extract of the leaves $\left(\mathrm{IC}_{50}\right.$ values $50.0 \%$ at $0.1 \mathrm{v} / \mathrm{v}$ and $80.0 \%$ at $\left.0.2 \mathrm{v} / \mathrm{v}\right)$, aqueous extract of the roots $\left(\mathrm{IC}_{50}\right.$ values $52.0 \%$ at $0.1 \mathrm{v} / \mathrm{v}$ and $90.0 \%$ at $0.2 \mathrm{v} / \mathrm{v})$ and the methanolic extract of the roots $\left(\mathrm{IC}_{50}\right.$ value $72 \%$ at 0.1 $\mathrm{v} / \mathrm{v})$ showed insecticidal activity against $P$. xylostella, while the methanolic extract of the leaves was inactive against the moths tested. The cabbage leaves were used as control. In addition, from the methanolic extract of the leaves two known compounds were isolated: a flavonol glycoside derivative, hyperin (1) and a drimane-type sesquiterpenoid, albicanol (2) were isolated using different chromatographic methods. The structures of these compounds were stablished based on 1D and 2D NMR measurements and comparison with the reported spectroscopic data in the literature. This is the first study reporting the occurrence of drimane-type sesquiterpenoids in the family of Chenopodiaceae. The results showed that C. album has chemical components that could be used as insecticides agents against P. xylostella.
\end{abstract}

Copy Right, IJAR, 2019 All rights reserved.

\section{Introduction:-}

Plutella xylostella (L.) (Lepidoptera, Plutellidae), also known as diamondback moth is the major limiting factor of cruciferous crops production in tropical areas throughout the world. Diamondback moth attacks only plant species belonging to the family of Cruciferae, with several Brassica crops being the most important hosts, especially early in the season before cultivated crops are available. Protection of Brassica crops from damage often requires the use of synthetic insecticides to plant foliage, and this could be a cause of resistance to the insecticides (Dickson et al., 
1990; Machekano et al., 2017; Vale et al., 2015). The synthetic insecticides have been the main control strategy for this pest. Due to insecticidal resistance for synthetic agents, research in this area is needed to find and develop new control strategies that are more environmentally friend and more durable. Promising approaches include the development of new natural occurring products derived from plants. Modern agriculture aims to reduce continuous applications of synthetic chemical pesticides for pest control. Botanical insecticides are good alternatives to synthetic pesticides, as they have lower environmental hazard, are biodegradable and can be shortly used before harvesting.

In search of natural biopesticides, the roots and leaves of Chenopodium album (Chenopodiaceae) were investigated. In this paper, we wish to report the insecticidal properties of the powders of the roots and the leaves, the aqueous and the methanolic extracts prepared form the roots and leaves of C. album, respectively, as well as the identification of a flavonoid glycoside derivative, hyperin (1) (Güvenalp \& Demirezer, 2005) and a drimane-type sesquiterpenoid, albicanol (2) (Asakawaet al. 1992). The structure of the compounds 1 and 2 were stablished based on comparison of their 1D and 2D NMR data with reported in the literature. This is the first example describing the identification of a drimane-type sesquiterpenoid metabolite in species belonging to the family of Chenopodiaceae.

C. album is an annual shrub and widely distributed in Africa, Asia, Northern America, and Europe. The plant has been used in folk medicine due to its antifungal, antipruritic and hypotensive properties, and insecticidal effects (AlSnafi, 2015). The mixture of C. ambrosoides and C. album has been used in Mozambique for the treatment of anaemia in goats and cows (Jansen \& Mendes, 1991). These bioactivities include the use of the crude extracts and pure isolated compounds, which justify the traditional uses (Agrawal et al., 2014). The major chemical constituents isolated from different parts of the plant include terpenoids, phenols, lignins, alkaloids, flavonoids, glycosides, saponins (Al-Snafi, 2015; Horioet al., 1993; Lavaudet al., 2000), and cinnamic acid amides (Cutilloet al., 2003).

\section{Material and methods:-}

\section{Plant material collection:-}

Samples of the roots and the leaves of C. album were collected in Boane District in Maputo Province. The specie was authenticated at the Herbarium Unit of Department of Biological Sciences, Faculty of Science of Eduardo Mondlane University, by comparison with an existing specimen with a voucher No. 225. The roots and leaves were dried in shadow at room temperature in Department of Chemistry, Faculty of Science of Eduardo Mondlane University until use. The selection of the plant was based on the literature survey due to its insecticidal effects.

\section{Rearing of $\mathbf{P}$. xylostella under laboratory conditions}

The B. oleacera var. acephala (cabbage) leaf was used as standard to compare the toxicity of the botanical material, and was used as host plant for rearing the P. xylostella. For growing cabbage, the seeds were showed in suitable trays containing a Plantmax substrate in the Greenhouse of the Faculty of Agronomy and Forest Engineering at Eduardo Mondlane University in Maputo, Mozambique, which after 35 days were transplanted into the definitive vessels in the number of 30. Subsequently, standards techniques for the cultivation of Brassica species were adopted for their production. The insects were raised in the Laboratory of Plant Physiology in the same Faculty. To begin the rearing the insects, the pupae were collected on cabbage plantations growing in the Faculty, and after the emergence, the adults were released in cages containing $8 \mathrm{~cm}$ disc of cabbage leaf placed on a filter paper disc of same size, slightly moistened with distilled water. The paper was laid over a transparent plastic cup with the opening facing down, the cabbage leaf being raised into the transparent cages, where the oviposition occurred. At the apex of the container with $2.3 \mathrm{~cm}$ opening, this was used for fixing a cotton sponge soaked in aqueous solution of honey, which was fastened as a small bundle in the opening. In each cage, the circular lateral openings were covered with an A4 paper. The cabbage leaf discs were removed from the cages and transferred to Petri dishes until hatching of the larvae that were transferred to the plastics bowls with cabbage leaves replaced when necessary, until the larvae reached the second instar. The larvae were collected using a spatula and placed in plastic bowls sealed with a plastic film with small holes made to allow air circulation.

\section{Preparation of plant powders and extracts:-}

The air-dried roots and leaves of $C$. album were separately grinded into fine powder and stored in the cold and dry place until use. The aqueous and methanolic extracts of the leaves and the roots powders (1/3 m/v of vegetal material) obtained by maceration $(72 \mathrm{~h})$ of both parts of this plant were tested for their lethal effect. 


\section{Isolation of compounds:-}

$15 \mathrm{~mL}$ of the methanolic extract of the leaves were diluted in water and then extracted with $\mathrm{n}$-hexane, chloroform and ethylacetate, to obtain three main fractions. The chloroformic fraction was subjected to the column chromatography for preliminary clean up using as eluent system a mixture of n-Hexane:EtOAc (1:1). Several fractions were collected. Fraction F3 was submitted to P-TLC in n-hexane:EtOAc (1:2 to 1:5) to yield a quercetin flavonol glycoside derivative, hyperin $(\mathbf{1}, 7.1 \mathrm{mg})$ and a drimane-type sesquiterpenoid, albicanol $(\mathbf{2}, 13.6 \mathrm{mg})$.

\section{Insecticidal activity:-}

The toxicity of plant material was assayed in the second instar larvae of $P$. xylostella using the leaf disc method. The concentration $(\mathrm{m} / \mathrm{v})$ of the aqueous and methanolic extracts were prepared according to the methodology described in the literature (Torres et al., 2006). To allow the subsequent calculations of the $\mathrm{LC}_{50}$, preliminary tests were initially carried out to define the limit of concentrations that causes $95 \%$ to $100 \%$ mortality of larvae (Medeiros et al., 2005). Cabbage discs with $8 \mathrm{~cm}$ in diameter were immersed in each sample over a period of 10 minutes to allow the extract to adhere to the entire surface of the cabbage leaf. The liquid soap was used as adherent. After immersion of the cabbage leaf discs, they were left outdoors for drying and thereafter transferred to Petri dishes containing a filter paper slightly moistened with distilled water. One hundred larvae of P. xylostella in the second instar were confined to each treatment for a period of $72 \mathrm{~h}$. three replicates were made in each treatment. The cabbage discs were daily changed and the Petri dishes were covered to prevent larvae from escaping. After the period of $72 \mathrm{~h}$, the mortality of the larvae as function of concentration was recorded for each treatment.

\section{Statistical analysis:-}

The statistical evaluation of the results regarding with the study of the insecticidal activity of the plant material of the C. album was made to determine the mean values of larvae mortality in three replicates of each treatment. Significant statistical difference $\mathrm{p}<0.05$ were made using ANOVA with the Turkey test at $5 \%$ probability, from the statistical package SPSS version 20.

\section{Results and discussions:-}

\section{Phytochemical screening:-}

From the methanolic extract of the leaves were isolated a flavonol glycoside derivative, hyperin (1) and a drimanetype sesquiterpenoids (2). The structures of the compounds were established based on the analysis of their NMR experimental data. Drimane-type sesquiterpenoids were identified for the first time in Chenopodiaceae plants. This class of compounds occur mainly in the plant species of the families of Polygonaceae and Canellaceae. However, they can be found in other plant families such as Aizoaceae, Thelypderidaceae and Umberlifferace and they are known to possess various biological activities including insecticidal, antifungal, antibacterial, antiviral, cytotoxic, plant-growth and antifeedent properties (Jansen \& De Groot, 2004).<smiles></smiles><smiles>C=C1CC[C@H]2C(C)CCCC2(C)[C@H]1CO</smiles>

Figure 1:-Chemical structures of the compounds present in C. album leaves

Table 1:- ${ }^{13} \mathrm{C}-\mathrm{NMR}$ data of compounds 1and $2(\mathrm{MeOD}, 100 \mathrm{MHz})$

\begin{tabular}{|l|l|l|}
\hline Carbon & $\mathbf{1}$ & $\mathbf{2}$ \\
\hline 1 & - & 39.1 \\
\hline 2 & 158.3 & 19.8 \\
\hline 3 & 135.2 & 41.9 \\
\hline 4 & 178.9 & 32.8 \\
\hline 5 & 163.0 & 55.4 \\
\hline
\end{tabular}




\begin{tabular}{|c|c|c|}
\hline 6 & 101.3 & 24.6 \\
\hline 7 & 167.2 & 38.7 \\
\hline 8 & 95.7 & 155.2 \\
\hline 9 & 158.5 & 61.1 \\
\hline 10 & 105.0 & 39.1 \\
\hline 11 & & 56.0 \\
\hline 12 & & 102.5 \\
\hline 13 & & 15.5 \\
\hline 14 & & 20.9 \\
\hline 15 & & 32.9 \\
\hline $1^{\prime}$ & 122.2 & \\
\hline $2^{\prime}$ & 114.8 & \\
\hline $3^{\prime}$ & 146.2 & \\
\hline 4' & 148.5 & \\
\hline 5 & 117.6 & \\
\hline $6^{\prime}$ & 122.9 & \\
\hline $1 "$ & 105.6 & \\
\hline $2 "$ & 73.2 & \\
\hline $3^{\prime \prime}$ & 74.5 & \\
\hline 4" & 69.8 & \\
\hline $5 "$ & 77.1 & \\
\hline 6" & 61.9 & \\
\hline
\end{tabular}

\section{Insecticidal evaluation:-}

When the insecticidal effects of the leaves powder was assayed, the elimination of all moths on the second day of the experiment was observed, while with the roots powder, the total elimination was observed on the third day of the experiment. The high mortality values were observed on the second day of treatment with the leaves powder $\left(\mathrm{IC}_{50}\right.$ value 100 at both samples amounts 0.1 and $0.3 \mathrm{~g}$ ) differs with the observed for the roots powder $\left(\mathrm{IC}_{50}\right.$ values 77.5 and at 0.1 and $0.3 \mathrm{~g}$, respectively. This could be attributed to the fact that the samples were collected before fructification, in which at this stage we could suggest that no translocation of compounds responsible for the insecticidal effect to the fruit. Also, the active ingredients are distributed differently in various parts of the same plant.

The aqueous extracts of the leaves and the roots $(0.1 \mathrm{v} / \mathrm{v})$ showed insecticidal activity against the mots with $\mathrm{IC}_{50}$ value of 50.0 and 52.5, respectively. This activity was also observed by Tavares and Vendramim (2005) when used the same plant extracts and same strain with minimal insecticidal activity of $50 \%$. At $0.2 \mathrm{v} / \mathrm{v}$ of concentration, the aqueous extracts of the leaves and the roots showed the $\mathrm{IC}_{50}$ values of 80 and 90 on the second day of the treatment (Table 2). From these observations could be concluded that the insecticidal effects depend on the concentration and the effect increases with concentration.

The methanolic extract of the roots $(0.1 \mathrm{v} / \mathrm{v})$ showed activity with $\mathrm{IC}_{50}$ value of 75.0 , while the methanolic extract of the leaves, at same concentration was inactive $\left(\mathrm{IC}_{50}<50\right)$ against the moths assayed. Iannacone and Quispe (2004) observed $73 \%$ of mortality of moths when used the methanolic extract of the roots of $\mathrm{C}$. album that confirmed our results. Peterson et al. (1989) suggested on a study done with C. ambrosioides that the compounds responsible on insecticidal activity could not be extracted by high polarity solvents, like methanol. However, by using solvents with medium or low polarity, like chloroform or $n$-hexane, in which they found that most of the compounds present on the n-hexane extract contain mainly long-chain hydrocarbons and fatty acids derivatives. In all experiments, using aqueous and methanolic solutions of extracts were not observed significant differences between samples with the same concentration. The absence of insecticidal effect on methanolic extract could be attributed to in the fact the insecticidal compounds are found in low polarity solvent extracts. The Table 1 summarizes the results of the insecticidal effect of $C$. album. The presence of insecticidal activities in several plant families could be attributed to the presence of secondary metabolites such as: phenolic and aromatic compounds, alkaloids and terpenoids. These compounds are found in several plant families. Out of 1,800 plant species with insecticidal properties investigated worldwide against the target insects, only 82 were reported to be effective against the diamondback moth (Chandrashekharaiah, Satish, Vasudev, Arya, \& Narasimhamurthy, 2015). 
Table 2:-Insecticidal effects of C. album

\begin{tabular}{|c|c|c|}
\hline Treatment & Concentration & \%mortality \\
\hline Leaves powder & $0.1(\mathrm{~g} / \mathrm{mL})$ & $100 \pm 00$ \\
& $0.3(\mathrm{~g} / \mathrm{mL})$ & $77.5 \pm 1.52$ \\
\hline Roots powder & $0.1(\mathrm{~g} / \mathrm{mL})$ & $95.0 \pm 1.59$ \\
\hline Aqueous leaves & $0.3(\mathrm{~g} / \mathrm{mL})$ & $50 \pm 5.02$ \\
\hline Aqueous roots & $0.1(\mathrm{v} / \mathrm{v})$ & $50.2 \pm 90$ \\
\hline Methanolic leaves & $0.2(\mathrm{v} / \mathrm{v})$ & $90 \pm 1.29$ \\
\hline Methanolic roots & $0.1(\mathrm{v} / \mathrm{v})$ & $45 \pm 3.78$ \\
\hline Positive control & $0.2(\mathrm{v} / \mathrm{v})$ & $72.5 \pm 0.80$ \\
\hline
\end{tabular}

\section{Conclusions:-}

In the present study, the roots and leaves powders as well as their aqueous and methanolic extracts were evaluated for their insecticidal activity. The results showed that both powders and the aqueous extracts could be used as insecticides against diamondback moth in cabbage. In addition, from the literature has been reported that drimanetype sesquiterpenoids possess insecticidal activity. This could suggest the use of C. album in search of natural insecticidal compounds.

\section{Acknowledgments:-}

The author wish to acknowledge the Eduardo Mondlane University for providing the necessary facilities and financial support to carry out research. And the Mozambican Fundo Nacional de Investigacao (FNI) for the help in publishing this work.

\section{References:-}

1. Agrawal, M. Y., Agrawal, Y. P., \& Shamkuwar, P. B. (2014).Phytochemical and biological activities of Chenopodium album. International Journal of Pharmacy and Technology Research, 6(1), 383-391.

2. Al-Snafi, A. (2015). The chemical constituents and pharmacological effects of Chenopodium album - an review. International Journal of Pharmacological Screening Methods, 5(1), 10-17.

3. Asakawa, Y., Hashimoto, T., Mizuno, Y., Tori, M., \& Fukazawa, Y. (1992).Cryptoporic acids A-G, drimanetype sesquiterpenoid ethers of isocitric acid from the fungus Cryptoporusvolvatus. Phytochemistry, 31(2), 579592.

4. Chandrashekharaiah, M., Satish, S. C., Vasudev, K., Arya, V. V., \& Narasimhamurthy, G. M. (2015). Efficacy of plant and aboriginal preparations against diamondback moth, Plutella xylostella (L.) (Lepidoptera: Plutellidae). Journal of Entomology and Zoology Studies, 3(4), 18-23.

5. Cutillo, F., Abrosca, B. D., Dellagreca, M., Di, C., Golino, A., Previtera, L., \& Zarrelli, A. (2003). Cinnamic acid amides from Chenopodium album : effects on seeds germination and plant growth. Phytochemistry, 64, 1381-1387.

6. Dickson, M. H., Shelton, A. M., Eigenbrode, S. D., Vamosy, M. L., \& Mora, M. (1990).Selection for resistance to diamondback moth (Plutella xylostella) in cabbage. Horticulture Science, 25(12), 1643-1646.

7. Güvenalp, Z., \& Demirezer, L. O. (2005). Flavonol Glycosides from Asperula arvensis L. Turk. J. Chem., 29, $163-169$.

8. Horio, T., Yoshida, K., Kikuchi, H., Kawabata, J., \& Junya, M. (1993). A phenolic amide from roots of Chenopodium album. Phytochemistry, 33(4), 807-808.

9. Iannaconne, J., \& Quispe, C. (2004). Efecto insecticida de dos extractos vegetales sobre el gorgojo del maíz, Sitophilus zea mais Motschulsky, 1855 (Coleoptera: Curculionidae) en Perú. Revista Peruana de Entomología, 44(1), 81-87.

10. Jansen, B. J. M., \& De Groot, A. (2004). Occurrence, biological activity and synthesis of drimane sesquiterpenoids. Natural Product Reports, 21(4), 449-477.

11. Jansen, P. C. M., \& Mendes, O. (1991). Plantas Medicinais - Seu Uso Tradicional Em Moçambique. (I. do Partido, Ed.) (T4 ed.). Maputo, Mozambique: Ministério da Saúde Gabinete de estudos de Medicina Tradicional. 
12. Lavaud, C., Voutquenne, L., Bal, P., \& Pouny, I. (2000). Saponins from Chenopodium album. Fitoterapia, 71, 338-340.

13. Machekano, H., Mvumi, B., \& Nyamukondiwa, C. (2017). Diamondback Moth, Plutella xylostella (L.) in Southern Africa: Research Trends, Challenges and Insights on Sustainable Management Options. Sustainability, 9(2), 91.

14. Medeiros, C. A. M., Boiça, A. L., \& Torres, A. L. (2005). Efeito de extratos aquosos de plantas na oviposição da traça-das-crucíferas, em couve. Bragantia, 64(2), 227-232.

15. Peterson, G. S., Kandil, M. A., Abdallah, M. D., \&Farag, A.-A.A. (1989) .Isolation and Characterisation of Biologically-Active Compounds from Some Plant Extracts. Pesticides. Sci., 25, 337-342.

16. Tavares, M. A. G. C., \& Vendramim, J. D. (2005). Bioactividade da Erva-de-Santa-Maria, Chenopodium ambrosioides L., sobre Sitophilus zea mais Mots. (Coleoptera: Curculionidae). Neotropical Entomology, 34(2), 319-323.

17. Torres, Adalci Leite; Boiça Júnior, Arlindo Leal; Medeiros, Cesar Augusto Manfré; Barros, R. (2006). Efeito de extratos aquosos de. Bragantia, 65(3), 447-457.

18. Vale, A. P., Santos, J., Melia, N., Peixoto, V., Brito, N. V., \& Oliveira, M. B. P. P. (2015). Phytochemical composition and antimicrobial properties of four varieties of Brassica oleracea sprouts. Food Control, 55, 248256. 